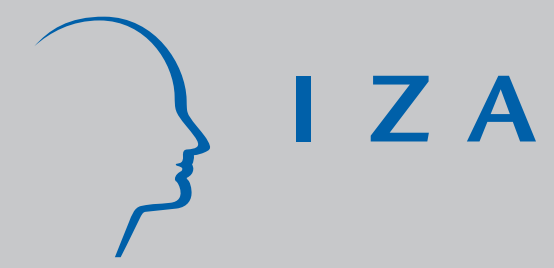

IZA DP No. 206

The Evaluation of Community-Based Interventions: Group Randomization, Limits and Alternatives

Christoph M. Schmidt

Rob Baltussen

Rainer Sauerborn

October 2000 


\title{
The Evaluation of Community-Based Interventions: Group-Randomization, Limits and Alternatives
}

\author{
Christoph M. Schmidt \\ University of Heidelberg, CEPR, London and IZA, Bonn \\ Rob Baltussen \\ Department of Tropical Hygiene and Public Health, University of Heidelberg \\ Rainer Sauerborn \\ Department of Tropical Hygiene and Public Health, University of Heidelberg
}

Discussion Paper No. 206

October 2000

\author{
IZA \\ P.O. Box 7240 \\ D-53072 Bonn \\ Germany \\ Tel.: +49-228-3894-0 \\ Fax: +49-228-3894-210 \\ Email: iza@iza.org
}

This Discussion Paper is issued within the framework of IZA's research area Project Evaluation. Any opinions expressed here are those of the author(s) and not those of the institute. Research disseminated by IZA may include views on policy, but the institute itself takes no institutional policy positions.

The Institute for the Study of Labor (IZA) in Bonn is a local and virtual international research center and a place of communication between science, politics and business. IZA is an independent, nonprofit limited liability company (Gesellschaft mit beschränkter Haftung) supported by the Deutsche Post AG. The center is associated with the University of Bonn and offers a stimulating research environment through its research networks, research support, and visitors and doctoral programs. IZA engages in (i) original and internationally competitive research in all fields of labor economics, (ii) development of policy concepts, and (iii) dissemination of research results and concepts to the interested public. The current research program deals with (1) mobility and flexibility of labor markets, (2) internationalization of labor markets and European integration, (3) the welfare state and labor markets, (4) labor markets in transition, (5) the future of work, (6) project evaluation and (7) general labor economics.

IZA Discussion Papers often represent preliminary work and are circulated to encourage discussion. Citation of such a paper should account for its provisional character. 
IZA Discussion Paper No. 206

October 2000

\section{ABSTRACT \\ The Evaluation of Community-Based Interventions: Group-Randomization, Limits and Alternatives*}

The context of community-based interventions presents formidable problems for any evaluation analysis. Group-randomized studies do possess ideal properties in theory, but in practice, grouprandomization might not be a feasible alternative at all or group-randomized studies might be contaminated. Thus, the decisive advantage of randomized controlled trials, that they and only they provide for a completely convincing identification strategy in the presence of observable and unobservable confounders, is lost. There are alternative strategies for the identification of treatment effects also in the case of unobservable confounders, however, although they specifically require unverifiable a priori information to be available. Moreover, when using nonexperimental data, one can often easily extend sample size at low cost, and thus estimate parameters very precisely; therefore, for any particular situation the relative attractiveness of experimental and non-experimental approaches should be explored.

JEL classification: $\quad$ C24, C92, I18

Keywords: Randomized controlled trials, self-selection, econometric evaluation, observational studies

Christoph M. Schmidt

Department of Economics (Econometrics)

University of Heidelberg

Grabengasse 14

69177 Heidelberg

Germany

Tel.: +49-6221-54 2955

Fax: +496221543640

Email: Schmidt@uni-hd.de

\footnotetext{
* We are grateful to Boris Augurzky and Claire Weinberg for their comments. This work was (in part) supported by the collaborative research grant 'SFB 544' of the German Research Foundation (DFG).
} 


\section{Background}

Community-based interventions are interventions that provide simultaneous access to a given form of treatment to all individuals within a community, even though the intensity of exposure to actual treatment may vary across community members. Examples are water supply and sanitation programs to reduce diarrhoeal diseases (Blum and Feachem 1983), vitamin A supplementation to reduce childhood mortality (Sommer et al. 1986), health education to reduce heart diseases (Farquhar et al. 1990, Fortmann et al. 1995, Green et al. 1995, Murray 1995). Since such interventions are costly endeavors competing for substantial shares of the limited health budget, the evaluation of their effect on health outcomes is imperative.

In its formal approach to the evaluation of community-based interventions, the epidemiological literature concentrates on the probabilistic characterization of group-randomized controlled trials (e.g. Murray 1997, 1998). The presence of within-community correlation of individual outcomes and the difficulty to sample a sizeable number of communities are recognized herein as important idiosyncrasies of community-based interventions. Suggested remedies are the adaptation of the variance formulae (Cornfield 1978, Donner et al. 1981) and the statistical control for observable confounding factors via regression or matching (Donner 1985, 1987, Hsieh 1988, Shipley et al. 1989).

Yet, it is also well known that for many community-based interventions a randomized controlled trial might not be a feasible approach at all, for political, ethical, logistic, or financial reasons, or that a randomized trial might be contaminated by influences beyond the control of the researcher designing the study (Altman 1986, Smith 1987, Hall and Aaby 1990, Smith and Morrow 1991, Kirkwood et al. 1997). In that case epidemiological contributions usually resort to a quasiexperimental approach: it is hoped that the statistical control for observable baseline differences between non-experimental treatment and control communities both in the levels and in secular trends might approach the balancing of confounders that is the aim of randomized treatment assignment in an experiment (Fortmann et al. 1995, Murray 1995).

More generally, it is suggested that researchers assemble a host of corroborating evidence, for instance on pre/post, treatment/control, and adopters/non-adopters comparisons (Kirkwood et al. 1997), although none of these comparisons would by itself provide for a convincing evaluation strategy. Since it appears that the problem of unobservable confounders cannot be addressed, it 
transpires that the only hope is to simply involve more communities in future trials (Fortmann et al. 1995). By contrast, the recent literature in statistics and econometrics (e.g. Angrist et al. 1996, Heckman 1997) has developed alternative strategies for the analysis of non-experimental data which can be successful in the presence of unobservable confounders, building on a priori information about various aspects of the process, for instance on the determinants of the choice of treatment regime.

This paper explores the potential of such alternative non-experimental evaluation strategies in the context of community-based interventions. To this end, it formally analyzes the statistical evaluation problem when interventions are community-based and discusses the limits of randomized controlled trials. It is argued here that for community-based interventions the decisive advantage of randomized controlled trials, that they and only they provide for a completely convincing identification strategy in the presence of observable and unobservable confounders, is lost. Moreover, when using non-experimental data, one can often easily extend sample size at low cost, and thus estimate parameters very precisely; therefore, it will be argued here that for any particular situation the relative attractiveness of experimental and non-experimental approaches should be explored.

The second section of the paper provides a formal statement of the evaluation problem for community-based interventions, the third section discusses group-randomized controlled trials as the typical epidemiological approach when interventions are community-based, the fourth section analyzes the methodological problems with this evaluation strategy and suggests alternative evaluation approaches, and the final section argues for the existence of a meaningful trade-off between experimental and non-experimental evaluation strategies.

\section{Community-Based Interventions: The Evaluation Problem}

The evaluation of the impact of community-based interventions on individual health outcomes inevitably requires more data than could be available in any analysis, a censoring problem. Ideally, one would like to measure for each individual $i$ under study, the potential outcome $Y_{l i}$ that would be realized if the individual received the treatment, and compare this to the potential outcome $Y_{0 i}$ that would be realized if the individual remained untreated. This, however, is obviously impossible, irrespective of whether one wants to analyze experimental or non-experimental data. What is 
observed, instead, is the actual outcome $Y_{i}$ which corresponds to $Y_{l i}$ if the individual is treated and to $Y_{0 i}$ otherwise ${ }^{1}$.

Despite the unavoidable problem of observability at the individual level, one might still be able to assess average gains from treatment. Let $T_{i}$ be an indicator variable that takes the value unity if individual $i$ receives treatment and zero otherwise. Then the mean effect of treatment on the treated,

$$
\Delta \equiv E\left(Y_{1 i} \mid T_{i}=1\right)-E\left(Y_{0 i} \mid T_{i}=1\right),
$$

appropriately summarizes individual gains $Y_{l i}-Y_{0 i}$ for all individuals who receive treatment ${ }^{2}$. Given that our interest is in this population parameter, two conceptually distinct questions have to be addressed, identification and statistical inference. Firstly, would it be possible to infer the correct parameter with infinite precision by (of course hypothetically) collecting abundantly many observations from the underlying population? - Then, this population parameter is said to be identified from observable data ${ }^{3}$. Secondly, what are the properties of any estimator of this entity in a sample of limited size?

Following this terminology, the mean outcome of treated individuals $E\left(Y_{l i} \mid T_{i}=1\right)$ is identified from observable data, while their mean outcome had they not received treatment $E\left(Y_{0 i} \mid T_{i}=1\right)$ is not. Even an abundantly large sample on treatment participants would never be able to reveal anything on their potential outcomes had they not participated. The evaluation problem is the problem of

1

This approach to conceptualizing the evaluation problem is known as the Rubin Causal Model in the statistics literature (Rubin 1974) and as the Switching Regression Model (Quandt 1972) in the econometrics literature, and has predecessors also in epidemiology (Greenland and Robins 1986); for a discussion of these parallel developments see Angrist et al. 1996 and the comments by Heckman and Moffitt. An early seminal contribution to the evaluation literature in econometrics is Heckman and Robb (1985). In this paper, we take the outcome measure as given, although problems of defining an appropriate outcome measure may be quite relevant for applied work.

2

Alternatively, one might be interested in other evaluation parameters such as the mean effect of treatment on individuals randomly drawn from the population, $\tilde{\Delta} \equiv E(Y)-E(Y)$. Concentration in much of the evaluation literature is on $\Delta$.

3

In statistical terms, this first question asks whether we can find any consistent estimator for the parameter at all. Please note that an unbiased estimator does not have to be consistent, while a biased estimator might very well be consistent. 
finding an entity that is identified from observable data which can replace the unidentified $E\left(Y_{0 i} \mid T_{i}=1\right)$ in the construction of an estimate for expression (1).

It might be that the mean outcome of individuals who do not receive treatment $E\left(Y_{0 i} \mid T_{i}=0\right)$ could serve as this entity, if selection into treatment is statistically independent of its effects. This property is ensured in an individual-level clinical trial by randomizing some individuals out of the potential treatment group into a control group and by preserving the composition of treatment and control groups by close monitoring as the trial proceeds. When working with non-experimental data, however, individuals who received treatment and those who did not have been selected into these two groups by a process that might, among other aspects, reflect individual gains from treatment.

Consequently, using in applied work an estimate of $E\left(Y_{0 i} \mid T_{i}=0\right)$ in the comparison group of those not receiving the treatment as a replacement for the estimate of $E\left(Y_{0 i} \mid T_{i}=1\right)$ in the construction of expression (1) for the treatment group, might be a very poor evaluation strategy. This is the principal reason for the clear preference for experimental evaluation strategies in the epidemiological literature. It will be discussed below, however, that more sophisticated approaches to observational data than this primitive calculation of the comparison-group mean might provide for superior evaluation strategies.

To give further structure to the discussion, presume that the underlying distribution of the potential outcomes $Y_{1 i}$ and $Y_{0 i}$ across the population is characterized by a conditional (on individual and community characteristics $X_{i}$ ) probability distribution, and that the available data comprise, in addition to observed outcomes $Y_{i}$ and characteristics $X_{i}$, the indicator of treatment $T_{i}$ and a further indicator $Z_{i}$. Think of this latter variable as shifting the cost of participation such that it is a predictor of participation, albeit an imperfect one $\left(Z_{i}=1\right.$ represents low cost, $Z_{i}=0$ high cost, ceteris paribus). In effect, while the indicator $Z_{i}$ does affect observed outcomes $Y_{i}$ only via its impact on whether treatment is received or not, it is nevertheless related to the assignment to treatment and control groups. Consequently, $Z_{i}$ is unrelated to potential outcomes conditional on the actual treatment status captured by $T_{i}$. 
This variable is referred to as an instrumental variable in the remainder of the paper ${ }^{4}$. It could for instance measure the distance to the treatment site $\left(Z_{i}=1\right.$ reflecting comparatively easy access). In a community context, it might reflect the availability of administrative staff from a previous intervention $\left(Z_{i}=0\right.$ implying that a new staff would have to be hired and trained). - In these examples, this variable would typically be one out of several determinants of treatment participation. Another example would be an indicator taking the value unity for all individuals in a controlled randomized trial who are assigned to treatment, and zero otherwise (Heckman 1996b) - then, $Z_{i}=0$ would indicate the prohibitively high cost involved in circumventing the assignment to the control group. Hence $Z_{i}=T_{i}$.

Based on this setup, the next sections of the paper will discuss the two fundamental questions of any evaluation analysis, identification, and statistical inference. This discussion will be shaped by the particular context of community-based interventions: the assignment to and the reception of treatment will be on the community level, but outcome measurement will be on the level of individuals. We will argue that this particular context makes the consideration of the possible tradeoff between the risk of identification failure and precision imperative ${ }^{5}$. Perhaps even more dramatically, the attempt to proceed as in a randomized controlled trial, although underlying theoretical conditions are not met, might lead to failure also in larger samples.

\section{Community-Based Interventions: The Received Wisdom}

Since the exposure to a community-based intervention varies across the members of the community and since it is typically very difficult to assess if and to what degree an individual has been exposed to the program, a completely individual-based evaluation of the intervention would make little sense. Instead, the most promising approach to evaluation is to exploit the variation of treatment status across communities - the treatment indicator $T_{i}$ takes the identical value for all individuals in the

4

The special case of a dichotomous instrument is discussed here for illustrative purposes; the arguments presented are unaltered in their substance when the instrument is continuous or when there are several instruments.

5

This is not to say that sample size considerations are irrelevant for the evaluation of individual-level interventions, but in that context it is easy to justify the isolated discussion of identification. 
same community -, while retaining outcome measurement at the level of the individual (Murray 1997, 1998).

It is undisputable that, when considering interventions delivered on the individual level, a complete balancing on observable and unobservable characteristics between treatment and control groups is achieved by randomization and subsequent monitoring of compliance, if only the sample size is large enough. In its unequivocally preferred choice of concrete evaluation strategy, the current epidemiological literature adapts this idea of a randomized controlled trial (RCT) to the community-level context (Murray 1997, 1998). Formally, the instrumental variable $Z_{i}$ is taken to be an indicator of randomly determined - at the community level - assignment status and the conditional treatment probabilities are $P\left(T_{i}=1 \mid Z_{i}=1\right)=1$ and $P\left(T_{i}=0 \mid Z_{i}=0\right)=1$, respectively.

Such group-randomized studies intend to approach the desirable properties of randomized controlled studies performed at the individual level: by balancing various sources of bias on aspires to infer the average treatment effect from the difference of the average outcomes of individuals in randomly selected participating communities and of individuals in randomly selected control communities,

(2) $\Delta=E\left(Y_{i} \mid Z_{i}=1\right)-E\left(Y_{i} \mid Z_{i}=0\right)$.

That is, the identification assumption made here is $E\left(Y_{0 i} \mid Z_{i}=1\right)=E\left(Y_{0 i} \mid Z_{i}=0\right)$ where all observations are on individuals in communities which applied for treatment but then were assigned to treatment or control groups by a random mechanism ${ }^{6}$. Whereas the applied literature documents many obstacles arising to group-randomization in practice (Altman 1986, Smith 1987, Hall and Aaby 1990, Smith and Morrow 1991, Kirkwood et al. 1997), the formal epidemiological literature generally builds on this paradigm of group-randomization and the fundamental possibility of successful identification via group-randomization is typically not questioned further. This perspective implies that by increasing the number of communities involved in the trial, the correct treatment effect will be revealed eventually with infinite precision.

6

Note that all individuals in the treatment group have been randomized into this group, that is $Z_{i}=1$, and that all individuals in the control group have been randomized out, that is $Z_{i}=0$. The comparison in (2) can therefore also be written with indicator $Z_{i}$ replaced by $T_{i}$. 
Questions of precision are recognized in the epidemiological literature to be of importance, though, as a consequence of limited sample sizes (Smith and Morrow 1991). Much of the discussion concerns the possible presence of observable confounding factors $X_{i}$, that is factors that influence potential outcomes and that - due to sample size limitations - are not balanced completely by the process of randomization. This balancing is desirable, however, since the population means are weighted averages of conditional means, for instance $E\left(Y_{1 i} \mid T_{i}=1\right)=\mathrm{I}_{X \mid T} E\left(Y_{1 i} \mid X_{i}, T_{i}=1\right)$, with $\mathrm{I}_{X \mid T}$ denoting integration over the distribution of observable confounders as it is displayed by the individuals for whom $T_{i}=1$.

An imbalance of observable confounders in the sample used for analysis would not provide for the correct weighting of conditional means in the treatment and control groups. The remedy suggested for this problem is the statistical control for these confounders via regression or matching (Donner 1985, 1987, Hsieh 1988). However, due to the application of group-randomization, if sample size were to grow beyond any limit, randomization would serve to eliminate this problem completely, even without particular attention to observable confounders.

A second problem of precision concerns any remaining imbalance of unobservable confounders in a sample of limited size, since individual outcomes are likely to be correlated within communities. In a group-randomized study this is also a problem of inference, not of identification: this problem would diminish as sample size were growing to be large ${ }^{7}$. Since intervention delivery is at the community level, however, the possible number of communities involved in the study is necessarily restricted in practice. The suggested remedy for this problem is to allow for random community effects in the statistical model; the major implication is an adaptation of the corresponding variance formulae to account for the loss in the precision of point estimates (e.g. Cornfield 1978, Donner et al. 1981).That, nevertheless, many applied researchers obviously mistake observations on individuals within the same community as providing independent information on the process has been criticized in a long series of epidemiological articles (Donner et al. 1990, Loevinsohn 1990, Simpson et al. 1995).

7

If observations on outcomes are available for the same individuals in two or more time periods, it might be possible to difference out the time-persistent components of these unobservable confounders. Any remaining unobserved components are then time-dependent and may or may not be unrelated to choice of treatment. For the sake of clarity of presentation of the arguments, this will be left implicit in this paper. 
In the current epidemiological literature, the clear but mistaken conclusion from balancing these advantages and disadvantages of pursuing the group-randomization approach as compared with non-experimental studies seems to be that one should always favor experimental over nonexperimental approaches, since only they would ensure identification and since there are strategies to successfully address small sample problems. However, the next section will collect several reasons why we are not assured that randomization indeed works outside of the realm of individual-level clinical trials, irrespective of the number of communities involved in the analysis.

Where group-randomized trials are not feasible, the literature (Fortmann et al. 1995, Murray 1995, Kirkwood et al. 1997) suggests as the only available, but conceptually inferior alternative to proceed with the non-experimental data, replacing the unidentified $E\left(Y_{0 i} \mid T_{i}=1\right)$ in the construction of an estimate for expression (1) by $\mathrm{I}_{X \mid T=1} E\left(Y_{0 i} \mid X_{i}, T_{i}=0\right)$. This, of course, would be a satisfactory strategy only under the presumption that all unobservable confounders are balanced across treatment and comparison groups. Since the implied absence of any unobservable confounders is rarely palatable, any non-experimental approach at evaluation therefore appears as a weak competitor with low scientific merit. The only hope, then, seems to be increasing the number of communities involved in the trial (Fortmann et al. 1995, Murray 1995) in order to at least reduce problems of statistical inference.

However, within the statistical framework built up in the previous sections, and contrary to the presumption displayed by the epidemiological literature, it will be argued below that nonexperimental studies are not confined to balancing observable confounders. Instead, an instrumental variables approach is suggested as a remedy for an imbalance in unobservable confounders.

\section{Identification Problems in Group-Randomized Studies}

\section{Problems}

The particular context of community-based interventions generates serious problems for the identification strategy that is generally favored by the literature, the adaptation of the RCT paradigm from its clinical origins to the group-randomized setting. These problems extend beyond the usually recognized limitation of sample size. In essence, while individual patients at a treatment center can hardly control whether they will be assigned to the treatment or the control group, and while the 
compliance of members of both groups can be monitored easily, randomization and monitoring quickly reach their limits of practical feasibility when the units to be randomized are political entities.

First, group-randomization might simply not be a feasible strategy from the outset, for ethical, political, logistic, and financial reasons. For instance, the applied literature on the evaluation of community-based interventions documents serious ethical objections against group-randomization: In the evaluation of treatments that have a high probability of being effective, it may be considered unethical to carry out an evaluation study involving a control group or area from which the effective intervention is withheld (Kirkwood et al. 1997). Then, the only feasible choice is a non-experimental study.

Randomization of communities might also face strong political objections - communities are not simply large-sized individuals, their decisions are rather the consequence of the complex aggregation of their members' preferences. Thus, it might be significantly more difficult to generate the widespread pre-intervention support for the randomized study across a sizeable number of communities that would be the prerequisite for a group-randomized design and that is so easily ensured with individual patients in a clinical setting. Furthermore, the political influence on the assignment process can also take more subtle forms (Fortmann et al. 1995): communities that suffer more from a particular problem or simply more wealthy communities will lobby for better access to promising interventions. In addition, there might be strong indirect influence of political pressure through the influence of the status quo on the assignment choice. Administrators might feel tempted to assign those communities to the treatment group which display favorable characteristics such as nutritional status, the participation in a previous trial or a well-developed infrastructure. This is not merely a problem of sample size and, thus, cannot be solved by involving more communities in the trial.

Moreover, whenever the program is to be delivered at a large scale, it may be impossible for logistic reasons to generate a setting in which neighboring communities can actually be assigned to treatment and control groups by a random process. For instance, consider the case of mass-media campaigns that have to be delivered at a regional level. Again, this is not simply a problem of sample size. Finally, one might simply not be able to acquire the appropriate sample size: in many situations the cost of assuring randomization of sufficiently many units at the community level might be prohibitive, particularly when evaluating interventions in developing countries. For instance, in their 
survey of community-based trials Donner et al. (1990) typically document a low number of communities involved. If for any of these reasons randomization cannot be attempted seriously to begin with, appealing to any superior theoretical properties of group-randomized trials is not of any value for actual applications.

Second, even where one can engage into group-randomization, the community context can work against the construction and preservation of randomized treatment and control groups. That is, what is set up as a group-randomized study might be contaminated by processes beyond the control of the researcher designing the analysis. Such problems arise at various stages of treatment assignment and intervention delivery, since compliance with the assignment and the program are difficult to monitor. At every stage of the process, communities might explicitly decide to drop out from treatment or control groups altogether or they might reduce or increase their effort in supporting the delivery in a less conspicuous fashion ${ }^{8}$.

In terms of the formal setup, as a consequence of both these fundamental problems of randomization or subsequent contamination the assumption underlying impact estimation in grouprandomized settings, $E\left(Y_{0_{i}} \mid T_{i}=1\right)=E\left(Y_{0_{i}} \mid T_{i}=0\right)$, is no longer justified. The selection process might depend predictably on characteristics of the community; then, modeling the process generating participation and continued compliance might be a viable alternative to increased monitoring efforts and one might base the analysis on a conditional independence assumption $E\left(Y_{0 i} \mid X_{i}, T_{i}=1\right)=$ $E\left(Y_{0 i} \mid X_{i}, T_{i}=0\right)$ instead. If the selection process depends on unobservable community characteristics, though, this identification strategy will no longer be successful, irrespective of all attempts to account for within-cluster correlations. As a consequence, identification of treatment effects might not be ensured in a group-randomized setting.

\section{Alternative Strategies}

The fact that - even conditional on observable confounding factors - the most obvious identification strategies, (a) the comparison of means of individual outcomes in treatment and control groups based on group-randomization, and (b) the comparison of means of individual outcomes in treatment

8

For the sake of the brevity of presentation, we do not discuss further sources of contamination: for instance, there might be a spillover of treatment across treatment and control communities, or the reality of being involved in a randomized trial might change behavior. 
and non-experimental comparison groups, might both be unable to ensure identification, does not preclude identification of treatment effects completely. Instead, researchers might still be able to select a more promising approach. Such alternative evaluation strategies necessarily involve additional a priori information such as functional form assumptions in a behavioral model of the participation process, restrictions on the variability of the impact of the intervention across the treatment group, or exclusion restrictions in the determination of outcomes in an instrumental variables approach.

To illustrate our arguments, we will concentrate here on a single alternative identification strategy, the use of instrumental variables (IV). In the formal setup of section 2, the instrument $Z_{i}$ was introduced as a variable that is (i) being unrelated to potential outcomes given the treatment assignment - conditional mean independence -, but (ii) related to receiving the treatment. In section 3 this instrument was specifically taken to be synonymous with an indicator of randomization which led to a successful solution to the evaluation problem. In this section, however, it was argued that the assumptions underlying the RCT paradigm, $P\left(T_{i}=1 \mid Z_{i}=1\right)=1$ and $P\left(T_{i}=0 \mid Z_{i}=0\right)=1$ might fail to hold in a community context ${ }^{9}$. As long as our data contains any variable with properties (i) and (ii), however, one might modify the comparison made in (2) to reflect the fact that now $P\left(T_{i}=1 \mid Z_{i}=1\right)<1$ and $P\left(T_{i}=0 \mid Z_{i}=0\right)<1$, respectively ${ }^{10}$.

For a constant treatment effect, for instance, it is easy to demonstrate that the ratio

$$
\Delta=\frac{E\left(Y_{i} \mid Z_{i}=1\right)-E\left(Y_{i} \mid Z_{i}=0\right)}{P\left(T_{i}=1 \mid Z_{i}=1\right)-P\left(T_{i}=1 \mid Z_{i}=0\right)}
$$

identifies the mean effect of treatment on the treated, since

9

For the sake of keeping the presentation as simple as possible, we do not explicitly condition on observable characteristics $X_{i}$ in the subsequent formulae. It should be kept in mind that in most cases arising in practice one would want to control for such observable factors; the properties of the instrumental variable discussed here are then meant to hold conditional on $X_{i}$, not unconditional properties.

10

Of course, the indicator of randomization in a contaminated experiment might serve as an instrument in the IV approach, if information is available on outcomes for individuals whose communities were randomized into treatment and control groups but which subsequently did not comply with that assignment. 


$$
\begin{aligned}
& E\left(Y_{i} \mid Z_{i}=1\right)-E\left(Y_{i} \mid Z_{i}=0\right)= \\
& E\left(Y_{0 i}+T_{i}\left(Y_{1 i}-Y_{0 i}\right) \mid Z_{i}=1\right)-E\left(Y_{0 i}+T_{i}\left(Y_{1 i}-Y_{0 i}\right) \mid Z_{i}=0\right)= \\
& E\left(Y_{1 i}-Y_{0 i} \mid T_{i}=1\right) \cdot P\left(T_{i}=1 \mid Z_{i}=1\right)- \\
& E\left(Y_{1 i}-Y_{0 i} \mid T_{i}=1\right) \cdot P\left(T_{i}=1 \mid Z_{i}=0\right)= \\
& E\left(Y_{1 i}-Y_{0 i} \mid T_{i}=1\right) \cdot\left[P\left(T_{i}=1 \mid Z_{i}=1\right)-P\left(T_{i}=1 \mid Z_{i}=0\right)\right] .
\end{aligned}
$$

That is, the comparison between mean outcomes of individuals in the treatment group and in the control group is replaced by a comparison of mean outcomes of groups distinguished by the value of the instrument; the denominator of equation (3) scales this difference to account for the imperfect correlation of the treatment indicator with the instrument ${ }^{11}$.

While the IV approach has a long tradition in econometrics, its potential to identify treatment effects is a matter of recent debate in the statistics and econometrics literature (Imbens and Angrist 1994, Angrist et al. 1996, Heckman 1997). Under the mild condition of a non-negligible impact of the instrument on the choice of treatment regime, the IV estimator identifies the mean effect of treatment on the treated (expression (1)) when the treatment effect is constant across individuals. Identification of this parameter is also achieved when the response to treatment varies among individuals, if the choice of the treatment regime does not depend on the unobserved gain from entering treatment ${ }^{12}$. As a consequence, as long as a researcher is able to detect a plausible

11

It is easy to verify that in the special case of an uncontaminated randomized controlled trial the denominator is unity and the numerator is the difference of mean outcomes of treatment and control groups, and thus expression (3) is identical to expression (2).

12

The situation becomes more intricate when treatment effects are heterogeneous and selection into treatment depends on these individual effects - the IV estimator then identifies the mean effect of treatment only for those individuals in the treatment group for whose treatment choice the instrument is pivotal, the local average treatment effect or LATE (see Imbens and Angrist 1994, Angrist et al. 1996, Heckman 1997, and Augurzky and Schmidt 2000 for an illustration in the context of community-based interventions). 
instrument in contaminated experimental or in non-experimental data, even the most severe obstacles to identification can be overcome.

Consider, for instance, a community-based educational program, a smoking prevention program, say, in a situation which precludes an experimental evaluation. If those communities are more likely to participate in the program which - for reasons being unobservable to the researcher would have lower smoking rates even in the absence of the program, a comparison of the means of individual outcomes in treatment and non-experimental comparison communities will be misleading. However, community participation in the program may also depend on the current availability of administrative staff, which does not engage into the actual delivery, but is nevertheless indispensable for implementing the program. Presume further that the impact of the prevention program is constant across communities which decide to enroll in the program. An instrumental variables approach using staff availability as an instrument along the lines of expression (3) - notably a non-experimental evaluation strategy operating in the presence of unobserved confounders - will then identify successfully the effect of the smoking prevention program.

In the final section, we will argue that the possibility to sample a large number of observations may even make the analysis of non-experimental data the preferred strategy for the evaluation of a community-based intervention.

\section{Estimator Precision and the Trade-Off}

The context of community-based interventions presents formidable problems for any evaluation analysis that can often not be solved convincingly by appealing to the paradigm of randomized controlled trials. Group-randomized studies do possess ideal properties in theory, but in practice, group-randomization might not be a feasible alternative at all or - as has been argued here in contrast to the previous epidemiological literature - group-randomized studies might be contaminated. In that case, the decisive advantage of randomized controlled trials, that they and only they provide for a completely convincing identification strategy in the presence of observable and unobservable confounders, is lost.

There are alternative strategies for the identification of treatment effects also in that case, but they specifically require additional a priori assumptions to hold - it is the nature of such assumptions that one ultimately cannot verify them on the basis of evidence. This very necessity of having to 
impose unverifiable assumptions in the analysis has been the main criticism against non-experimental studies. As has been argued here, for evaluating community-based interventions, one cannot avoid this problem altogether by simply increasing the number of communities involved in grouprandomization.

In this paper, one potentially successful alternative identification strategy has been advocated in particular, the estimation of treatment effects using instrumental variables, either on the basis of contaminated experimental data or on the basis of non-experimental data. It was demonstrated that, as long as a researcher is able to detect a plausible instrumental variable in the data even the problem of unobservable confounders can be overcome. A randomization indicator will typically be an ideal instrument, since it is unrelated to potential outcomes by construction. Even if the communities' compliance with assignment is imperfect, one can identify the mean effect of treatment on the treated, as long as individuals do not know their idiosyncratic gain from treatment or do not influence their communities' participation behavior on the basis of this knowledge (for a numerical illustration see Augurzky and Schmidt 2000).

Moreover, if the principal advantage of group-randomized studies over and above nonexperimental studies, the successful identification of treatment effects, is in fact an issue of debate, then the question of precision moves into the center of considerations as well (see also Heckman and Robb 1985). This topic had clearly to stand back against the issue of identification in the context of individual-level interventions. When using non-experimental data, one can often easily extend sample size at low cost, and thus estimate parameters very precisely. Since there are non-experimental evaluation approaches credibly addressing the fundamental evaluation problem, IV-estimation being one of them, identification of treatment effects might be achieved with non-experimental data and this precision might be an important advantage.

However, it is demonstrated in Augurzky and Schmidt (2000) that the number of nonexperimental observations must typically exceed those of a competing experimental study by a large factor for the non-experimental approach to become the superior evaluation strategy. Thus, while it will be generally impossible to provide a common recipe for every possible intervention and context, for any particular situation the relative attractiveness of experimental and non-experimental approaches should be explored. 


\section{References}

Altman, David G. (1986) A Framework for Evaluating Community-Based Heart Disease Prevention Programs, Soc. Sci. Med. 22, 479-487.

Angrist, Joshua D., Guido W. Imbens, and Donald B. Rubin (1996) Identification of Causal Effects Using Instrumental Variables, Journal of the American Statistical Association 91, 444-455.

Augurzky, Boris and Christoph M. Schmidt (2000) The Evaluation of Community and Individual-based Interventions: Assessing Different Evaluation Strategies in a Monte Carlo Study, mimeo. Universität Heidelberg.

Blum D. and R. G. Feachem (1983) Measuring the Impact of Water Supply and Sanitation Investments on Diarrhoeal Diseases: Problems of Methodology, International Journal of Epidemiology 12, 357-386.

Cornfield, Jerome (1978) Randomization By Group: A Formal Analysis, American Journal of Epidemiology 108, 100-102.

Donner, Allan (1985) A Regression Approach to the Analysis of Data Arising From Cluster Randomization, International Journal of Epidemiology 14, 322-326.

Donner, Allan (1987) Statistical Methodology for Paired Cluster Design, American Journal of Epidemiology 126, 972-979.

Donner, Allan, N. Birkett, and C. Buck (1981) Randomization By Cluster: Sample Size Requirements and Analysis, American Journal of Epidemiology 114, 906-914.

Donner, Allan, K. Stephen Brown, and Penny Brasher (1990) A Methodological Review of Nontherapeutic Intervention Trials Employing Cluster Randomization, 1979-1989, International Journal of Epidemiology 19, 795-800.

Farquhar, J. W., S. P. Fortmann, J. A. Flora, B. Taylor, W. L. Haskell, P. T. Williams, N. Maccoby, and P. D. Wood (1990) Effects of Communitywide Education on Cardiovascular Disease Risk Factors: The Stanford Five-City Project, Journal of the American Medical Association 264, 359-365.

Fortmann, S. P., J. A. Flora, M. A. Winkleby, C. Schooler, C. B. Taylor, and J. W. Farquhar (1995), Community Intervention Trials: Reflections on the Stanford Five-City Project Experience, American Journal of Epidemiology 142, 576-586.

Green, Sylvan B., Donald K. Cole, Mitchell H. Gail, Steven D. Mark, David Pee, Laurence S. Freedman, Barry I. Graubard, and William R. Lynn (1995) Interplay between Design and Analyses for Behavioral Interventions Trials with Community as the Unit of Randomization, American Journal of Epidemiology 142, 587-593. 
Greenland, S. and J. M. Robins (1986) Identifiability, Exchangeability, and Epidemiological Confounding, International Journal of Epidemiology 15, 413-419.

Hall, A. J. and P. Aaby (1990) Tropical Trials and Tribulations, International Journal of Epidemiology 19, 777-781.

Heckman, James J. (1996a) Comment, Journal of the American Statistical Association 91, 459462.

Heckman, James J. (1996b) Randomization as an Instrumental Variable, The Review of Economics and Statistics 77, 336-341.

Heckman, James J. (1997) Instrumental Variables: A Study of Implicit Behavioral Assumptions in one Widely Used Estimator, Journal of Human Resources 32, 441-461.

Heckman, James J. and Richard Robb (1985) Alternative Methods for Evaluating the Impact of Interventions, in: Heckman, James and Burton Singer (eds.) Longitudinal Analysis of Labor Market Data, New York: Wiley, 156-245.

Hsieh F. Y. (1988) Sample Size Formulas for Intervention Studies With the Cluster as the Unit of Randomization, Statistics in Medicine 7, 1195-1202.

Imbens, Guido and Joshua Angrist (1994) Identification and Estimation of Local Average Treatment Effects, Econometrica 62, 467-476.

Kirkwood, Betty R., Simon N. Cousens, Cesar G. Victora, and Isabelle de Zoysa (1997) Issues in the Design and Interpretation of Studies to Evaluate the Impact of Community-Based Interventions, Tropical Medicine and International Health 2, 1022-1029.

Loevinsohn, Benjamin P. (1990) Health Education Interventions in Developing Countries: A Methodological Review of Published Articles, International Journal of Epidemiology 19, 788794.

Moffitt, Robert A. (1996) Comment, Journal of the American Statistical Association 91, 462465.

Murray, D. M. (1995) Design and Analysis of Community Trials: Lessons From the Minnesota Heart Health Program, American Journal of Epidemiology 142, 569-575.

Murray, D. M. (1997) Design and Analysis of Group-Randomized Trials: A Review of Recent Developments, Annals of Epidemiology 7, 69-77.

Murray D. M. (1998) Design and Analysis of Group-Randomized Trials, New York \& Oxford: Oxford University Press. 
Quandt, Richard (1972) Methods for Estimating Switching Regressions, Journal of the American Statistical Association 67, 306-310.

Rubin, Donald B. (1974) Estimating Causal Effects of Treatments in Randomized and Nonrandomized Studies, Journal of Educational Psychology 66, 688-701.

Simpson, J.M., N. Klar, and A. Donner (1995) Accounting for Cluster Randomization: A Review of Primary Prevention Trials, 1990 Through 1993, American Journal of Public Health 85, 13781383.

Shipley, M. J., P. G. Smith, and M. Dramaix (1989) Calculation of Power for Matched Pair Studies When Randomization is By Group, International Journal of Epidemiology 18, 457-461.

Smith, P. G. (1987) Evaluating Interventions Against Tropical Diseases, International Journal of Epidemiology 16, 159-166.

Smith, P. G. and R. H. Morrow (eds., 1991) Methods for Field Trials of Interventions Against Tropical Diseases, New York: Oxford University Press.

Sommer, A., I. Tarwotjo, E. Djunaedi, K. P. West, A. A. Loeden, R. Tilden et al. (1986) Impact of Vitamin A Supplementation on Childhood Mortality, Lancet i, 1169-1173. 


\section{IZA Discussion Papers}

\section{No Author(s) \\ 111 V. Sorm \\ K. Terrell \\ 112 L. Bellmann \\ T. Schank}

113 R. Euwals

114 G. Brunello

A. Medio

115 A. Cigno

F. C. Rosati

116 C. Belzil

117 S. Bender

A. Haas

C. Klose

118 M. A. Shields

M. E. Ward

119 A. Lindbeck

D. J. Snower

120

P. T. Pereira

P. S. Martins

121

J. C. van Ours

D. Munich

J. Svejnar

K. Terrell

123 J. Hunt

124 R. T. Riphahn

125 F. Büchel

J. R. Frick

126 J. Fersterer

R. Winter-Ebmer
Titel

Area

Date

Sectoral Restructuring and Labor Mobility:

A Comparative Look at the Czech Republic

$1 / 4$

$2 / 00$

Innovations, Wages and Demand for

5

$2 / 00$

Heterogeneous Labour: New Evidence from a

Matched Employer-Employee Data-Set

Do Mandatory Pensions Decrease Household

Savings? Evidence for the Netherlands

3

$2 / 00$

An Explanation of International Differences in

2

$2 / 00$

Education and Workplace Training

Why do Indian Children Work, and is it Bad for

3

$2 / 00$

Them?

Unemployment Insurance and Subsequent Job

3

$2 / 00$

Duration: Job Matching vs. Unobserved

Heterogeneity

IAB Employment Subsample 1975-1995.

Opportunities for Analysis Provided by the

Anonymised Subsample

Improving Nurse Retention in the British National

5

$2 / 00$

Health Service: The Impact of Job Satisfaction on Intentions to Quit

The Division of Labor and the Market for

Organizations

5

$2 / 00$

Does Education Reduce Wage Inequality?

Quantile Regressions Evidence from Fifteen

European Countries

5

$2 / 00$

Do Active Labor Market Policies Help Unemployed $\quad 4 / 6$

$3 / 00$

Workers to Find and Keep Regular Jobs?

Returns to Human Capital under the Communist

4

$3 / 00$

Wage Grid and During the Transition to a Market

Economy

Why Do People Still Live in East Germany? 1

$3 / 00$

Rational Poverty or Poor Rationality? The Take-up 3

$3 / 00$

of Social Assistance Benefits

The Income Portfolio of Immigrants in Germany -

Effects of Ethnic Origin and Assimilation. Or:

Who Gains from Income Re-Distribution?

Smoking, Discount Rates, and Returns to

5 
The Employment, Unemployment and

Unemployment Compensation Benefits of Immigrants

Is There a Wage Premium for Returning Irish

Migrants?

Unemployment and Productivity Growth: An

Empirical Analysis within the Augmented Solow Model

138 J. Zweimüller R. Winter-Ebmer

Continuous Training in Germany

Firm-specific Training: Consequences for Job

$3 / 00$ Mobility

139 R. A. Hart

Wages, Hours and Human Capital over the

$3 / 00$ Y. Ma

Life Cycle

140 G. Brunello

S. Comi

Education and Earnings Growth: Evidence from 11 European Countries

The Effects of Public Sector Sponsored Training on Individual Employment Performance in East Germany 
148 L. Goerke

149 R. Lalive J. C. van Ours J. Zweimüller J.-St. Pischke

151 M. Ward

152 J. J. Dolado

F. Felgueroso

J. F. Jimeno

153 A. S. Kalwij

M. Gregory

154 M. Gerfin

M. Lechner

155 J. Hansen

156 C. Dustmann

F. Fabbri

157 P. Apps

R. Rees

158 A. Björklund

T. Eriksson

M. Jäntti

O. Raaum

E. Österbacka

159 P.- J. Jost

M. Kräkel

160

M. Lofstrom

D. Treisman

G. Monusova
Does the Recent Success of Some OECD Countries in Lowering their Unemployment Rates Lie in the Clever Design of their Labour Market Reforms?

Employment Effects of Labour Taxation in an Efficiency Wage Model with Alternative Budget Constraints and Time Horizons

The Impact of Active Labor Market Programs and Benefit Entitlement Rules on the Duration of Unemployment

Unions and the Labor Market for Managers

3 $4 / 00$

Gender, Salary and Promotion in the Academic Profession

The Role of the Minimum Wage in the Welfare State: An Appraisal 1975-1999: A Panel Data Analysis

Microeconometric Evaluation of the Active Labour 6 Market Policy in Switzerland

The Duration of Immigrants' Unemployment Spells: $\quad 1 / 3$

Evidence from Sweden

$5 / 00$

Language Proficiency and Labour Market Per- 1 formance of Immigrants in the UK

$5 / 00$

Household Production, Full Consumption and $\quad 7$ the Costs of Children

Brother Correlations in Earnings in Denmark, 5 $5 / 00$ Finland, Norway and Sweden Compared to the United States

A Comparison of the Human Capital and Signaling Models: The Case of the Self-Employed and the Increase in the Schooling Premium in the 1980's

Public Employment and Redistributive Politics: 4 $6 / 00$

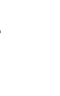


Barrachina

The Impact of Alcohol Consumption on Occupa- 5 tional Attainment in England

B. Nolan

Immigration into Ireland

168 G. S. Epstein

Social Harmony at the Boundaries of the Welfare 3

A. L. Hillman

State: Immigrants and Social Transfers

169 R. Winkelmann

Immigration Policies and their Impact: The Case of 1 New Zealand and Australia

Wages and the Demand for Health - A Life Cycle

between Skilled and Unskilled Blue-Collar Workers within Establishments: An Empirical Analysis with Data of Manufacturing Firms 
Joint Decisions on Household Membership and Human Capital Accumulation of Youths: The role of expected earnings and local markets

192 G. Brunello

193 A. Kunze

Absolute Risk Aversion and the Returns to 
198 M. Kreyenfeld

C. K. Spiess

G. G. Wagner

199 H. Entorf

200

T. Bauer

G. S. Epstein

I. N. Gang

201 T. J. Dohmen

G. A. Pfann

202

P. Francois

J. C. van Ours

203 J. M. Abowd

F. Kramarz

D. N. Margolis

T. Philippon

204 G. S. Epstein

205 A. L. Booth

M. Francesconi

J. Frank

206 C. M. Schmidt

R. Baltussen

R. Sauerborn
A Forgotten Issue: Distributional Effects of Day

3

$9 / 00$

Care Subsidies in Germany

Rational Migration Policy Should Tolerate Non-

1

$9 / 00$

Zero Illegal Migration Flows: Lessons from

Modelling the Market for Illegal Migration

What are Migration Networks?

$9 / 00$

Worker Separations in a Nonstationary Corporate 1

$9 / 00$

Environment

Gender Wage Differentials in a Competitive Labor

5

$9 / 00$

Market: The Household Interaction Effect

The Tail of Two Countries: Minimum Wages and 5

$9 / 00$

Employment in France and the United States

Labor Market Interactions Between Legal and

1

$10 / 00$ Illegal Immigrants

Temporary Jobs: Stepping Stones or Dead Ends? 1

$10 / 00$

The Evaluation of Community-Based Inter-

ventions: Group-Randomization, Limits and

6

$10 / 00$ 